\title{
Comment on "Effects of adipocyte-secreted factors on cell cycle progression in HT29 cells" published by Eur J Nutr
}

\author{
Jiezhong Chen · Xu-Feng Huang
}

Published online: 16 July 2009

(C) Springer-Verlag 2009

Obesity is associated with one-third of colon cancer. This is related to altered adipocyte-secreted factors including increased leptin and decreased adiponectin levels [3]. These risk factors cause increased signal pathways important in the carcinogenesis of colon cancer. We read with great interest the paper "Effects of adipocyte-secreted factors on cell cycle progression in HT29 cells" published in your journal [8]. The author screened 30 conditional adipocyte media on HT29 cell growth. In 11 of these, positive responses were found. Furthermore, the author also demonstrated that leptin upregulates ERK pathway, which was inhibited by genistein $[6,7]$.

In addition to ERK, leptin can also stimulate Src/PI3K/ Akt signal pathway [5]. Src/PI3K/Akt is also an important signal pathway in the carcinogenesis of colon cancer. Activation of the pathway can cause increased cell proliferation and decreased apoptosis in colon cancer as well as cytoskeleton change. Inhibition of this pathway has great potential for the treatment of colon cancer [2]. In Jaffe's study, leptin is shown to form lamellipodia via Src/rac and this is related to invasion of colon cancer. Thus, two carcinogenic signal pathways MAPK and Src/PI3K/Akt may have synergistic effect in leptin-causing carcinogenesis. Usually, these multiple signal pathways are necessary for the carcinogenesis [4]. Genistein also inhibits PI3K/Akt pathway except MAPK $[1,7]$.

J. Chen $(\varangle) \cdot$ X.-F. Huang $(\bowtie)$

Illawarra Health and Medical Research Institute,

University of Wollongong, Northfields Avenue,

Wollongong, NSW 2522, Australia

e-mail: jiezhong@uow.edu.au

X.-F. Huang

e-mail: xhuang@uow.edu.au
In conclusion, leptin may cause colon cancer through both PI3K/Akt and ERK pathways. Combinational inhibition could provide better therapy for the disease.

\section{References}

1. Banerjee S, Li Y, Wang Z, Sarkar FH (2008) Multi-targeted therapy of cancer by genistein. Cancer Lett 269:226-242

2. Chen J (2008) Is Src the key to understanding metastasis and developing new treatments for colon cancer? Nat Clin Pract Gastroenterol Hepatol 5:306-307

3. Chen J, Huang XF (2009) Obesity, the PI3K/Akt signal pathway and colon cancer. Obes Rev. 12 Jun 2009. [Epub ahead of print]

4. Chen J, McMillan NAJ (2008) Molecular basis of pathogenesis, prognosis and therapy in chronic lymphocytic leukaemia. Cancer Biol Ther 7:174-179

5. Jaffe T, Schwartz B (2008) Leptin promotes motility and invasiveness in human colon cancer cells by activating multiple signal-transduction pathways. Int J Cancer 123:2543-2556

6. Li Y, Sarkar FH (2002) Inhibition of nuclear factor kappaB activation in PC3 cells by genistein is mediated via Akt signaling pathway. Clin Cancer Res 8:2369-2377

7. Park SS, Kim YN, Jeon YK, Kim YA, Kim JE, Kim H, Kim CW (2005) Genistein-induced apoptosis via Akt signaling pathway in anaplastic large-cell lymphoma. Cancer Chemother Pharmacol $56: 271-278$

8. Schnäbele K, Roser S, Rechkemmer G, Hauner H, Skurk T (2009) Effects of adipocyte-secreted factors on cell cycle progression in HT29 cells. Eur J Nutr 48:154-161 (Epub ahead) 